\title{
Impact of Material and Lens Design on Repositioning Surgery of Toric Intraocular Lenses: A Single-Arm Meta-Analysis
}

\author{
Jing $W u\left(\mathbb{D},{ }^{1,2}\right.$ Changping Yang $\mathbb{D},{ }^{3}$ Yan Yin $\mathbb{D}^{4},{ }^{4}$ Linlin Liu $\mathbb{D},{ }^{5}$ and Hui Wang $\mathbb{D}^{5}$ \\ ${ }^{1}$ Department of Ophthalmology, Li Shui Municipal Central Hospital, Lishui, Zhejiang, China \\ ${ }^{2}$ Gannan Medical University, Ganzhou, Jiangxi, China \\ ${ }^{3}$ Department of Ophthalmology, Suichang People's Hospital, Lishui, Zhejiang, China \\ ${ }^{4}$ Second Affiliated Hospital of Shandong First Medical University, Taian, Shandong, China \\ ${ }^{5}$ Department of Ophthalmology, the First Affiliated Hospital of Gannan Medical University, Ganzhou, Jiangxi, China \\ Correspondence should be addressed to Jing Wu; wujing@gmu.edu.cn and Hui Wang; gyfywanghui@163.com
}

Received 10 November 2020; Accepted 22 December 2021; Published 27 January 2022

Academic Editor: Michele Figus

Copyright (c) 2022 Jing Wu et al. This is an open access article distributed under the Creative Commons Attribution License, which permits unrestricted use, distribution, and reproduction in any medium, provided the original work is properly cited.

\begin{abstract}
Aim. To analyze the pooled incidence rate in repositioning surgery by considering different materials and designs. Methods. All published studies investigating the repositioning surgery of toric intraocular lenses (IOLs) before September 1, 2020, were searched and evaluated. The R3.5.2 software was used to extract the data, and a single arm meta-analysis was performed. Results. 19 cases from 18 published studies articles were included in the meta-analysis. The pooled incidence rate in repositioning surgery was $2 \%\left(I^{2}=53 \%, P_{\text {heterogeneity }}<0.01\right)$. Plate and silicone IOLs had significantly higher incidence rates $(6 \%$ for each) than loop $(2 \%)$ and hydrophobic acrylate (2\%). Incidence rates of Acrysof, Staar, TECNIS, PhysIOL SA, T-flex 623T, and Microsil 6116TU groups were $1 \%(95 \%$ CI $[1 \%-2 \%]), 6 \%(95 \%$ CI $[4 \%-9 \%]), 3 \%$ (95\% CI $[2 \%-4 \%]), 1.40 \%(1 / 71), 3.03 \%(1 / 33)$, and $4.76 \%(1 / 21)$, respectively. Conclusions. The pooled incidence rate of repositioning surgery in IOLs was $2 \%$. Materials and designs would be risk factors for the rotational stability of the toric IOLs. Pooled incidence rates of the hydrophobic acrylate and loop group were lower than those of the silicone and plate group. Product identity is the main driver of heterogeneity.
\end{abstract}

\section{Introduction}

Toric intraocular lenses (IOLs) have been designed to restore visual acuity deteriorated by cataract and correct corneal astigmatism. Clinical studies have reported that toric IOLs have become a safe and effective method to treat cataract patients with preoperative refractive problems [1-3]. However, the precise positioning of the lens in relation to the intended alignment axis is crucial to achieve the intended effect. Toric IOL misalignment by approximately $1^{\circ}$ will reduce astigmatic correction by nearly $3.3 \%$, while a $30^{\circ}$ misalignment may not correct or increase the astigmatism $[4,5]$. Tognetto et al. [6] applied visual information fidelity to analyze the image quality at the IOL rotational step. Previous experiments have illustrated that image quality reduction was observed with a rotation of $30^{\circ}$; subsequently, the images at $45^{\circ}$ have the same quality without toric correction.
Thus far, only a small number of studies have examined the rotational stability of different toric IOLs. We aimed to evaluate the postoperative rotation and surgical repositioning of toric IOLs in different materials and designs, through this systematic review and meta-analysis.

\section{Methods}

2.1. Search Strategy and Inclusion Criteria. We screened the PubMed, Web of Science, Cochrane Library, ClinicalTrials.gov, CNKI, and Wanfang databases for original articles that were published before September 1, 2020. The searches were conducted using free combinations of the following keywords in both English and Chinese: "toric intraocular lenses," "toric IOL," "intraocular lens rotation," "toric intraocular lens," "toric phakic intraocular lens," and "rotation." Furthermore, we checked the reference lists of the papers selected. Literature search was independently 
conducted by two researchers (Jing $\mathrm{Wu}$ and Changping Yang), followed by resolving of any disagreements via consensus. The included studies met the following inclusion criteria: (1) original research papers regarding the repositioning surgery of toric rotation and (2) randomized controlled clinical trials, nonrandomized clinical trials, cohort studies, uncontrolled cohort studies, and case-control studies. We excluded studies with two or more lens subgroup variations which cannot be combined to obtain their respective incidence rates, along with those that did not satisfy one or more inclusion criteria.

\subsection{Data Extraction and Study Quality Assessment. Two} researchers (Jing Wu and Changping Yang) independently determined whether each study met the inclusion criteria. The following data were subsequently extracted from the included studies using a standardized form: name of the first author, publication year, country, age range, sample size, case, follow-ups, and toric types (shown in Supplementary Table 1). The characteristics of included toric IOLs are shown in Table 1. We used the Newcastle-Ottawa Scale [7] to evaluate the cohort and case-control studies. Quality of the nonrandomized interventional studies was evaluated using the methodological index for nonrandomized studies (MINORS) [8].

2.3. Statistical Analyses. Single-rate meta-analyses were carried out using the $\mathrm{R}$ statistical software package (version 3.5.2). We combined the experimental data and nonrandomized controlled trials with data from observational studies to perform a single-arm meta-analysis. We used five methods to combine the pooled incidence rate of repositioning surgery of toric intraocular lenses and eventually selected the Freeman-Tukey double arcsine transformations that were closest to normal distribution. Meta-analysis was individually performed for toric intraocular lenses of different materials. All meta-analyses were evaluated for heterogeneity using the chi-square based $I^{2}$ test and $Q$ test. An interstudy $I^{2}$ score $<50 \%$ or $P$ value $>0.10$ was considered nonheterogeneous; furthermore, we used a fixed-effects model for the meta-analysis. Conversely, we used the random-effects model for meta-analysis in the presence of heterogeneity. The meta-analysis results were based on the forest plot, and the effect size was the combined incidence rates and $95 \%$ confidence interval. Subgroup analysis was performed using the $\chi^{2}$ test, with $P<0.05$ indicating statistical significance. Additionally, we applied the funnel plot and Egger's linear regression to analyze the publication bias. We also performed the Duval and Tweedie nonparametric "trim and fill" procedure to further assess the possible effects of publication bias in our meta-analysis.

\section{Results}

3.1. Characteristics of Included Studies. After a systematic literature, we identified 701 articles, of which we thoroughly examined 22 full-length articles. We applied the inclusion and exclusion criteria to select 18 studies which included 14 nonrandomized interventional studies [9-21] and 4 cohort and case-control studies [1,22-24]. The remaining 4 articles were excluded due to the following reason: absence of sufficient information to obtain a definite incidence rate [25-28] (Figure 1).

Characteristics of the included studies have been summarized (shown in the supplementary table see here). We only included the toric IOL subgroup from 3 articles that compared toric and nontoric IOLs [1, 23, 24]. One article with two different datasets was considered as two separate studies [22]. In addition, 4 articles which reported a failure of the relocation surgery were included for subgroup analysis $[11,12,24,29]$. All included studies were determined to be moderate-to-high-quality studies.

3.2. Single-Arm Meta-Analysis. We included 19 cases from the 18 articles in the meta-analysis. The pooled incidence rate of repositioning surgery was $2.0 \%$ (95\% CI: $1 \%-3 \%)$ $\left(I^{2}=53 \%, P_{\text {heterogeneity }}<0.01\right)$ in toric IOLs. We used the random-effects model for the meta-analysis considering the presence of statistical heterogeneity (Figure 2).

We performed a subgroup analysis of the studies adjusted for haptic designs. The pooled incidence rate of repositioning surgery of plate-haptic toric was significantly higher than that of loop-haptic ( $2 \%$ and $6 \%$, respectively) (OR: 0.264, 95\% CI: 0.160-0.436, $P<0.001$ ) (Figure 3 and Table 2).

Furthermore, we performed a subgroup analysis of the studies adjusted based on the materials. Hydrophobic acrylic materials had a lower incidence rate of repositioning surgery of $2 \%$ (95\% CI: $1-2 \%)$, and silicone materials showed a significantly higher incidence rate for the need of a repositioning surgery of $6 \%$ (95\% CI: $4 \%-9 \%)$ (OR: $0.289,95 \%$ CI: 0.164-0.441, $P<0.001$ ) (Figure 4 and Table 2).

Subgroup analysis was also conducted based on products from different companies. We classified the included toric according to their respective companies or commercial names as Acrysof, Staar, TECNIS, PhysIOL SA, T-flex 623T, and Microsil 6116TU. There were 9 studies in the Acrysof, 5 studies in the Staar, and 2 studies in the TECNIS subgroups. The pooled incidence rate of repositioning surgery was $1 \%$ (95\% CI: $1 \%-2 \%$ ), 6\% (95\% CI: $4 \%-9 \%)$, and 3\% (95\% CI: $2 \%-4 \%$ ), respectively. Subgroups were compared via the list $\chi^{2}$ test, which revealed a statistically significant difference $\left(x^{2}=36.383 ; P<0.001\right)$ (Figure 5 and Table 2).

We further used the partitions of the $\chi^{2}$ method to perform pairwise comparison of multiple sample rates (Table 3). PhysIOL SA, T-flex 623T, and Microsil 6116TU were all included in one study, demonstrating incidence rates of $1.40 \%(1 / 71), 3.03 \%(1 / 33)$, and $4.76 \%(1 / 21)$, respectively.

All subgroup comparisons passed the criteria required for the heterogeneity test; subsequently, the fixed-effects models were used for meta-analysis.

3.3. Publication Bias. We used the $\mathrm{R}$ software with "metabias," and the Egger funnel plots are shown in Figure 6. The regression line in the Egger funnel plot did not pass the 0 
TABLE 1: Characteristics of toric IOLs included in the meta-analysis.

\begin{tabular}{|c|c|c|c|c|c|c|c|}
\hline Country & Company & Commercial name & $\begin{array}{l}\text { Spherical } \\
\text { power }\end{array}$ & Cylinder power & Design & Haptic & Material \\
\hline USA & Alcon & $\begin{array}{l}\text { Acrysof TIOL } \\
\text { SN60TT }\end{array}$ & $+6 \mathrm{D} \sim+34 \mathrm{D}$ & $+1.5 \mathrm{D} \sim+6.0 \mathrm{D}$ & Single-piece & Loop & $\begin{array}{c}\text { Hydrophobic } \\
\text { acrylic }\end{array}$ \\
\hline & & $\begin{array}{c}\text { Acrysof IQ toric IOL } \\
\text { SN6AT }\end{array}$ & $+6 \mathrm{D} \sim+34 \mathrm{D}$ & $+1.5 \mathrm{D} \sim+6.0 \mathrm{D}$ & $\begin{array}{l}\text { Aspheric } \\
\text { optic }\end{array}$ & Loop & $\begin{array}{l}\text { Hydrophobic } \\
\text { acrylic }\end{array}$ \\
\hline USA & $\begin{array}{c}\text { Abbott Medical } \\
\text { Optics }\end{array}$ & TECNIS & $+5 \mathrm{D} \sim+34 \mathrm{D}$ & $\begin{array}{c}1.00 \mathrm{D}, 1.50,2.25 \\
3.00,4.00 \mathrm{D}\end{array}$ & Single-piece & Loop & $\begin{array}{c}\text { Hydrophobic } \\
\text { acrylic }\end{array}$ \\
\hline USA & Staar & AA $4203 \mathrm{TF} / \mathrm{TL}$ & $+10 \mathrm{D} \sim+28 \mathrm{D}$ & $+2 \mathrm{D}, 3.5 \mathrm{D}$ & Single-piece & Plate & Silicone \\
\hline Germany & Human Optics & Microsil 6116TU & $-3 \mathrm{D} \sim+30 \mathrm{D}$ & $+2 \mathrm{D} \sim+12 \mathrm{D}$ & 3-Piece & $\begin{array}{l}\text { PMMA Z- } \\
\text { design }\end{array}$ & Silicone \\
\hline
\end{tabular}

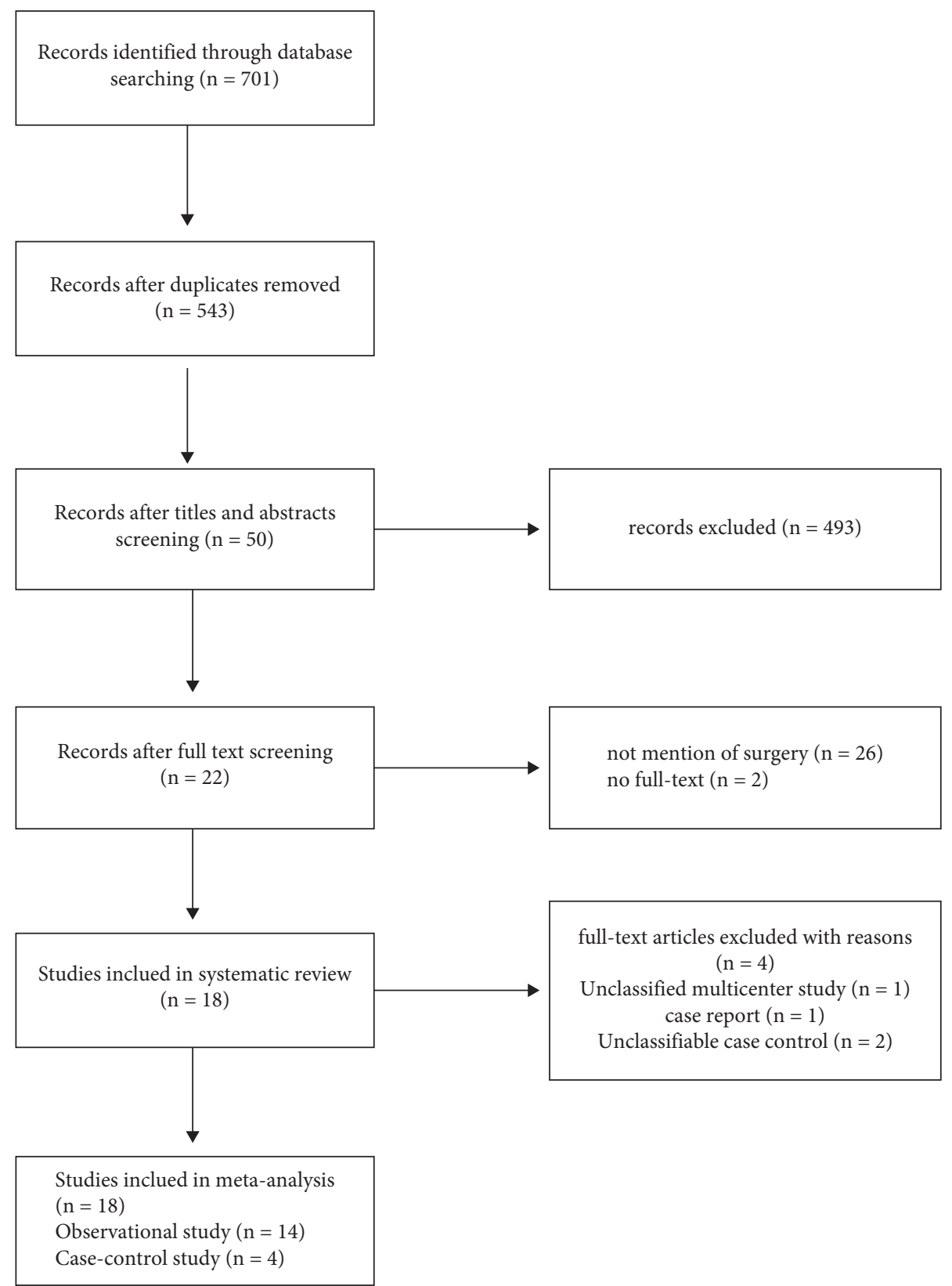

FIGURE 1: Flowchart demonstrating how the identified published studies were included in the meta-analysis. 


\begin{tabular}{|c|c|c|c|c|c|c|c|c|c|c|c|}
\hline Study & Events & Total & & & & & & Proportion & $95 \%$-CI & $\begin{array}{l}\text { Weight } \\
\text { (fixed \%) }\end{array}$ & $\begin{array}{c}\text { Weight } \\
\text { (random \%) }\end{array}$ \\
\hline Dardzhikova 2009 & 2 & 111 & $\frac{1}{1}$ & & & & & 0.02 & {$[0.00 ; 0.06]$} & 3.5 & 5.4 \\
\hline Venkataraman 2013 & 4 & 122 & $\frac{1}{1}$ & & & & & 0.03 & {$[0.01 ; 0.08]$} & 3.8 & 5.7 \\
\hline Miyake 2014 & 4 & 378 & + & & & & & 0.01 & {$[0.00 ; 0.03]$} & 11.7 & 8.9 \\
\hline Sun 2000 & 12 & 130 & : & & & & & 0.09 & {$[0.05 ; 0.16]$} & 4.0 & 5.9 \\
\hline Till 2002 & 5 & 100 & $\frac{1}{1 !} \pm$ & & & & & 0.05 & {$[0.02 ; 0.11]$} & 3.1 & 5.1 \\
\hline Chang 2003 & 3 & 55 & $\frac{1}{1}$ & & & & & 0.05 & {$[0.01 ; 0.15]$} & 1.7 & 3.4 \\
\hline Leyland 2001 & 2 & 22 & $\frac{i}{1:}$ & & & & & 0.09 & {$[0.01 ; 0.29]$} & 0.7 & 1.7 \\
\hline Ruhswurm 2000 & 1 & 37 & $\frac{1}{1}$ & & & & & 0.03 & {$[0.00 ; 0.14]$} & 1.2 & 2.6 \\
\hline De Silva 2006 & 1 & 21 & $\frac{1}{1}$ & & & & & 0.05 & {$[0.00 ; 0.24]$} & 0.7 & 1.6 \\
\hline Chang 2009 & 3 & 263 & $\frac{1}{4}$ & & & & & 0.01 & {$[0.00 ; 0.03]$} & 8.2 & 8.0 \\
\hline Xing 2010 & 1 & 46 & $\frac{i}{i}$ & & & & & 0.02 & {$[0.00 ; 0.12]$} & 1.4 & 3.0 \\
\hline Fu 2010 & 1 & 48 & $\frac{i}{i}$ & & & & & 0.02 & {$[0.00 ; 0.11]$} & 1.5 & 3.1 \\
\hline Vandekerckhove2018 & 1 & 71 & $\frac{1}{1:}$ & & & & & 0.01 & {$[0.00 ; 0.08]$} & 2.2 & 4.1 \\
\hline Molham 2011 & 1 & 33 & $\frac{1}{1:}$ & & & & & 0.03 & {$[0.00 ; 0.16]$} & 1.0 & 2.3 \\
\hline Lee $2018 \mathrm{~A}$ & 10 & 626 & $\div$ & & & & & 0.02 & {$[0.01 ; 0.03]$} & 19.4 & 10.0 \\
\hline Lee $2018 B$ & 20 & 647 & 1 & & & & & 0.03 & {$[0.02 ; 0.05]$} & 20.0 & 10.1 \\
\hline Waltz 2015 & 4 & 172 & $\frac{1}{1}$ & & & & & 0.02 & {$[0.01 ; 0.06]$} & 5.3 & 6.7 \\
\hline Holland 2010 & 1 & 256 & $+1:$ & & & & & 0.00 & {$[0.00 ; 0.02]$} & 7.9 & 7.9 \\
\hline Visser 2014 & 1 & 82 & $+1:$ & & & & & 0.01 & {$[0.00 ; 0.07]$} & 2.6 & 4.5 \\
\hline Fixed effect model & & 3220 & $\diamond$ & & & & & 0.02 & {$[0.01 ; 0.02]$} & 100.0 & -- \\
\hline Random effects model & & & $\diamond$ & & & & & 0.02 & {$[0.01 ; 0.03]$} & -- & 100.0 \\
\hline \multicolumn{3}{|c|}{ Heterogeneity: $I^{2}=53 \%, \tau^{2}=0.0017, p<0.01$} & 0.05 & 0.1 & 0.15 & 0.2 & 0.25 & & & & \\
\hline
\end{tabular}

FIGURE 2: The forest plot displaying the pooled incidence rate of repositioning surgery of toric IOL.

\begin{tabular}{|c|c|c|c|c|c|c|c|c|c|}
\hline Study & Events & Total & & & & Proportion & $95 \%-\mathrm{CI}$ & $\begin{array}{c}\text { Weight } \\
\text { (fixed \%) }\end{array}$ & $\begin{array}{c}\text { Weight } \\
\text { (random \%) }\end{array}$ \\
\hline Dardzhikova 2009 & 2 & 111 & $\frac{1}{1}$ & & & 0.02 & {$[0.00 ; 0.06]$} & 3.9 & 4.7 \\
\hline Venkataraman 2013 & 4 & 122 & $\frac{1}{1}$ & & & 0.03 & {$[0.01 ; 0.08]$} & 4.3 & 5.1 \\
\hline Miyake 2014 & 4 & 378 & $+\frac{1}{1}$ & & & 0.01 & {$[0.00 ; 0.03]$} & 13.2 & 13.2 \\
\hline Chang 2009 & 3 & 263 & +1 & & & 0.01 & {$[0.00 ; 0.03]$} & 9.2 & 9.9 \\
\hline Xing 2010 & 1 & 46 & $\frac{i}{1+}$ & & & 0.02 & {$[0.00 ; 0.12]$} & 1.6 & 2.1 \\
\hline Fu 2010 & 1 & 48 & 1 & & & 0.02 & {$[0.00 ; 0.11]$} & 1.7 & 2.1 \\
\hline Vandekerckhove2018 & 1 & 71 & $-\frac{1}{1}$ & & & 0.01 & {$[0.00 ; 0.08]$} & 2.5 & 3.1 \\
\hline Molham 2011 & 1 & 33 & 1 & & & 0.03 & {$[0.00 ; 0.16]$} & 1.2 & 1.5 \\
\hline Lee $2018 \mathrm{~A}$ & 10 & 626 & $\frac{i}{1}$ & & & 0.02 & {$[0.01 ; 0.03]$} & 21.9 & 18.8 \\
\hline Lee $2018 B$ & 20 & 647 & $i$ & & & 0.03 & {$[0.02 ; 0.05]$} & 22.7 & 19.2 \\
\hline Waltz 2015 & 4 & 172 & $i_{1}$ & & & 0.02 & {$[0.01 ; 0.06]$} & 6.0 & 7.0 \\
\hline Holland 2010 & 1 & 256 & +1 & & & 0.00 & {$[0.00 ; 0.02]$} & 9.0 & 9.7 \\
\hline Visser 2014 & 1 & 82 & $-i$ & & & 0.01 & {$[0.00 ; 0.07]$} & 2.9 & 3.6 \\
\hline \multirow{3}{*}{$\begin{array}{l}\text { Fixed effect model } \\
\text { Random effects model } \\
\text { Heterogeneity: } I^{2}=15 \%\end{array}$} & & 2855 & $\diamond$ & & & 0.02 & {$[0.01 ; 0.02]$} & 100.0 & -- \\
\hline & & & $\dot{\theta}$ & & & 0.02 & {$[0.01 ; 0.02]$} & -- & 100.0 \\
\hline & 0.0002 & $p=0.29$ & 0.05 & 0.1 & 0.15 & & & & \\
\hline
\end{tabular}

(a)

Figure 3: Continued. 


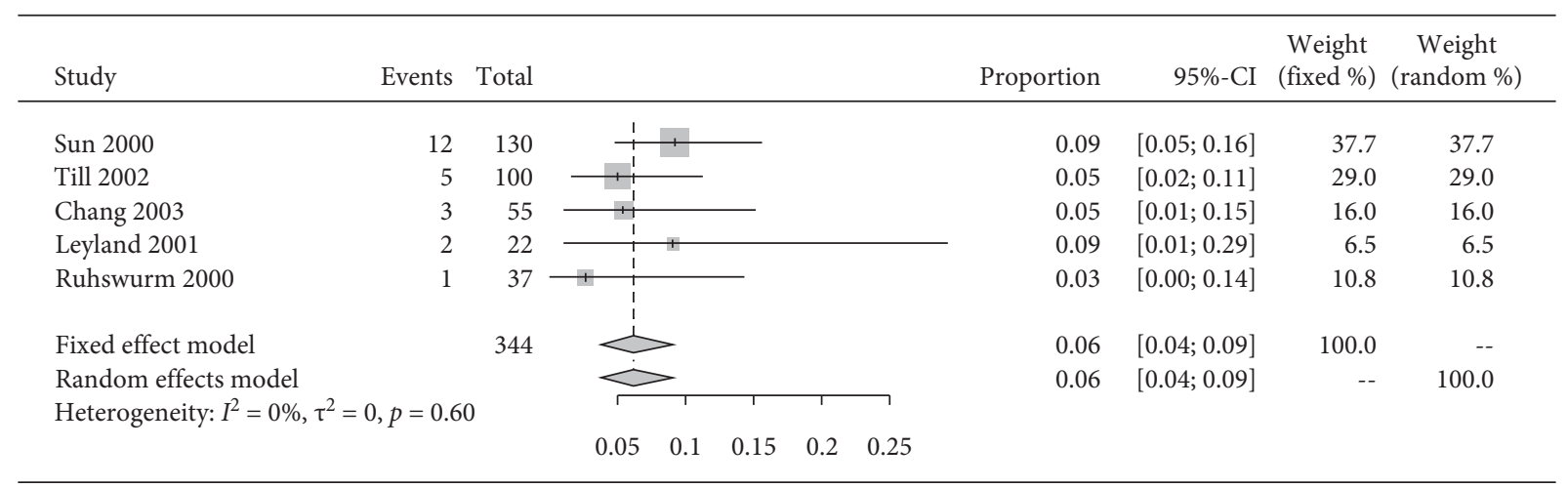

(b)

FIGURE 3: The forest plots displaying the pooled incidence rate of repositioning surgery of (a) loop-haptic toric IOLs and (b) plate-haptic IOLs.

TABLE 2: The pooled incidence rate of repositioning surgery with different subgroups.

\begin{tabular}{|c|c|c|c|c|c|c|c|}
\hline Variable & $\begin{array}{l}\text { Number of } \\
\text { articles }\end{array}$ & $\begin{array}{l}\text { Case/ } \\
\text { total }\end{array}$ & $\begin{array}{l}\text { Pooled estimate }[95 \% \\
\text { CI] }\end{array}$ & $\begin{array}{c}\text { Heterogeneity } I^{2 *} \\
(\%)\end{array}$ & $\begin{array}{c}Q \\
\text { value }\end{array}$ & OR $(95 \% \mathrm{CI})$ & $P$ value \\
\hline Total & 19 & $77 / 3220$ & $2[1-3]$ & 53 & 0.01 & & \\
\hline \multicolumn{8}{|l|}{ Haptic } \\
\hline Loop & 13 & $53 / 2855$ & $2[1-2]$ & 15 & 0.29 & \multirow{2}{*}{$\begin{array}{c}0.264 \\
(0.160-0.436) \\
1.00\end{array}$} & \multirow[t]{2}{*}{$\leq 0.001$} \\
\hline Plate & 5 & $23 / 344$ & $6[4-9]$ & 0 & 0.60 & & \\
\hline \multirow{2}{*}{$\begin{array}{l}\text { Material } \\
\text { Silicone } \\
\text { Hydrophobic } \\
\text { acrylic }\end{array}$} & 6 & $24 / 365$ & $6[4-9]$ & 0 & 0.63 & \multirow{2}{*}{$\begin{array}{c}1.00 \\
0.289 \\
(0.164-0.441)\end{array}$} & \multirow[b]{2}{*}{$\leq 0.001$} \\
\hline & 13 & $53 / 2855$ & $2[1-2]$ & 15 & 0.29 & & \\
\hline \multicolumn{8}{|l|}{ Products } \\
\hline Acrysof & 9 & $27 / 1932$ & $2[1-2]$ & 0 & 0.63 & $\begin{array}{c}0.198 \\
(0.112-0.349)\end{array}$ & 0.003 \\
\hline Staar & 5 & $23 / 344$ & $6[4-9]$ & 0 & 0.60 & 1.00 & $\leq 0.001$ \\
\hline TECNIS & 2 & $24 / 819$ & $3[2-4]$ & 0 & 0.58 & $\begin{array}{c}0.421 \\
(0.234-0.757)\end{array}$ & 0.003 \\
\hline PhysIOL SA & 1 & $1 / 71$ & & & & & \\
\hline T-flex $623 \mathrm{~T}$ & 1 & $1 / 33$ & & & & & \\
\hline Microsil $6116 \mathrm{TU}$ & 1 & $1 / 21$ & & & & & \\
\hline
\end{tabular}

* The chi-square test was used for two sample rates and list $\chi^{2}$ test was used for multiple sample rates. $P<0.05$ was considered statistically significant.

points, suggesting the presence of publication bias in the literature (Egger's $P=0.05184$ ). We performed a sensitivity analysis using the trim and fill method to rectify the same [30], which conservatively imputes the hypothetical negative unpublished studies to mirror the positive studies causing funnel plot asymmetry. After including 7 studies, it produced a symmetrical funnel plot (Figure 6). The pooled incidence rate and $95 \%$ CI did not change significantly $(1.18 \%, 95 \%$ CI, $0.46 \%-2.11 \%)$. Therefore, the results were considered to be robust and demonstrated a certain degree of reference significance.

\section{Discussion}

Toric IOLs have become an effective tool for patients to eliminate preoperative astigmatism. However, the rotational stability of toric is a significant factor that affects the performance of corrected visual acuity after cataract surgery.

We included of 19 studies comprising 3220 eyes, which showed a $2 \%$ pooled incidence rate of repositioning surgery. This incidence observed here was lower than that in previous studies (3-9.2\%) [23, 25]. Moreover, Oshika et al. [26] incorporated a large number of case series with 6431 eyes and reported that the overall incidence of repositioning surgery was $0.653 \%$. The lower incidence rate observed in the study may be associated with the distribution of the data. Here, we only included the studies with acrylic foldable toric IOLs; furthermore, all patients with a significant amount of misalignment did not undergo a repositioning surgery. Patients who had no obvious symptoms and those with IOL misalignment and did not consent for further surgical intervention were not included. 


\begin{tabular}{|c|c|c|c|c|c|c|c|c|c|}
\hline \multirow{2}{*}{$\begin{array}{l}\text { Study } \\
\text { Dardzhikova } 2009\end{array}$} & \multirow{2}{*}{$\begin{array}{r}\text { Events } \\
2\end{array}$} & \multicolumn{2}{|l|}{ Total } & & \multicolumn{2}{|r|}{ Proportion } & \multicolumn{2}{|c|}{$\begin{array}{r}\text { Weight } \\
\text { 95\%-CI (fixed \%) }\end{array}$} & \multirow{2}{*}{$\begin{array}{c}\begin{array}{c}\text { Weight } \\
\text { (random \%) }\end{array} \\
4.7\end{array}$} \\
\hline & & 111 & + & & & 0.02 & {$[0.00 ; 0.06]$} & 3.9 & \\
\hline Venkataraman 2013 & 4 & 122 & 1 & & & 0.03 & {$[0.01 ; 0.08]$} & 4.3 & 5.1 \\
\hline Miyake 2014 & 4 & 378 & +1 & & & 0.01 & {$[0.00 ; 0.03]$} & 13.2 & 13.2 \\
\hline Chang 2009 & 3 & 263 & +1 & & & 0.01 & {$[0.00 ; 0.03]$} & 9.2 & 9.9 \\
\hline Xing 2010 & 1 & 46 & $\frac{1}{1}$ & & & 0.02 & {$[0.00 ; 0.12]$} & 1.6 & 2.1 \\
\hline Fu 2010 & 1 & 48 & $\frac{1}{1}$ & & & 0.02 & {$[0.00 ; 0.11]$} & 1.7 & 2.1 \\
\hline Vandekerckhove2018 & 1 & 71 & $+\frac{1}{+1}$ & & & 0.01 & {$[0.00 ; 0.08]$} & 2.5 & 3.1 \\
\hline Molham 2011 & 1 & 33 & $\frac{1}{1}$, & & & 0.03 & {$[0.00 ; 0.16]$} & 1.2 & 1.5 \\
\hline Lee $2018 \mathrm{~A}$ & 10 & 626 & $\frac{1}{1}$ & & & 0.02 & {$[0.01 ; 0.03]$} & 21.9 & 18.8 \\
\hline Lee 2018B & 20 & 647 & 1 & & & 0.03 & {$[0.02 ; 0.05]$} & 22.7 & 19.2 \\
\hline Waltz 2015 & 4 & 172 & $\frac{1}{1}$ & & & 0.02 & {$[0.01 ; 0.06]$} & 6.0 & 7.0 \\
\hline Holland 2010 & 1 & 256 & +1 & & & 0.00 & {$[0.00 ; 0.02]$} & 9.0 & 9.7 \\
\hline Visser 2014 & 1 & 82 & $一 \frac{1}{1}$ & & & 0.01 & {$[0.00 ; 0.07]$} & 2.9 & 3.6 \\
\hline Fixed effect model & & 2855 & & & & 0.02 & {$[0.01 ; 0.02]$} & 100.0 & -- \\
\hline Random effects model & & & $\diamond$ & & & 0.02 & {$[0.01 ; 0.02]$} & -- & 100.0 \\
\hline \multicolumn{3}{|c|}{ Heterogeneity: $I^{2}=15 \%, \tau^{2}=0.0002, p=0.29$} & 0.05 & 0.1 & 0.15 & & & & \\
\hline
\end{tabular}

(a)

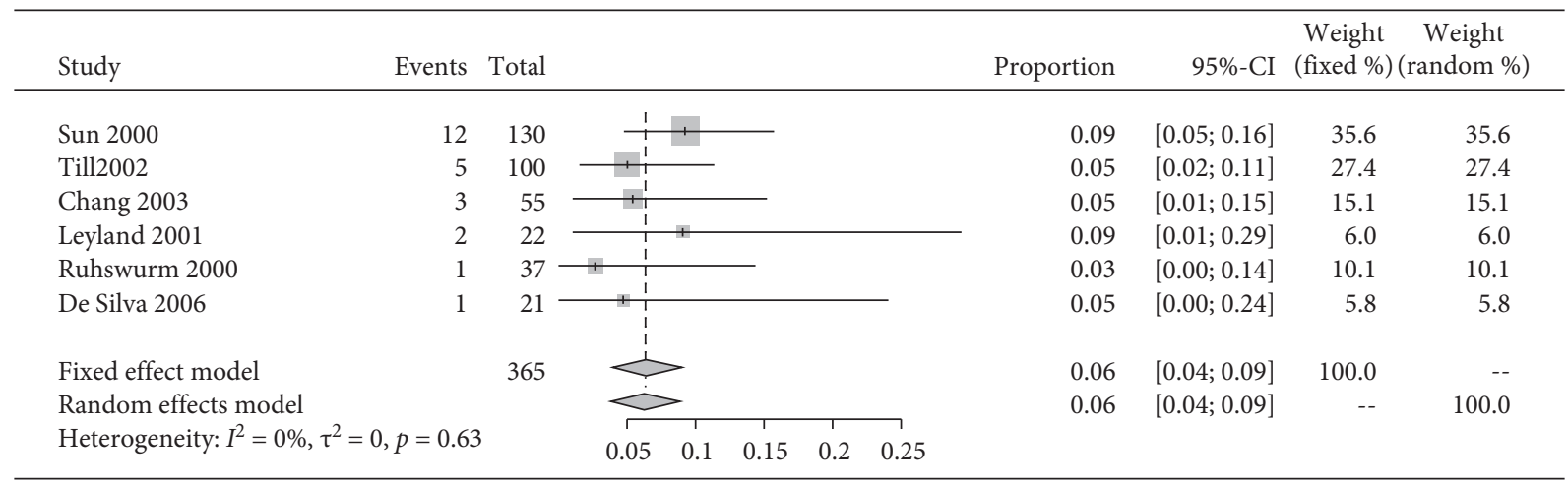

(b)

FIgURE 4: The forest plots displaying the pooled incidence rate of repositioning surgery of (a) hydrophobic acrylic material IOLs and (b) silicone material IOLs.

Materials used in the studies have demonstrated association with a certain degree rotation of toric IOLs. We observed that performing a subgroup analysis based on the materials demonstrated a significantly higher incidence rate of rotation in silicone IOLs than in hydrophobic acrylate IOLs (OR: 0.289, 95\% CI: 0.164-0.441, $P<0.001$ ). Lombardo et al. [31] reported that hydrophobic acrylic IOLs showed the highest adhesive properties, followed by hydrophilic acrylic IOLs, PMMA IOLs, and finally silicone IOLs. Linnola et al. [32] also demonstrated that acrylic IOLs had more fibronectin than silicone which had strongest adhesion with capsular bag. Therefore, hydrophobic acrylic IOLs had better rotational stability than the silicone IOLs. In addition, Draschl et al. [33] contrasted two group toric IOLs in the same design with different materials, which subsequently indicated that the hydrophobic acrylic IOLs were better than the hydrophilic IOLs. Here, we also found that the hydrophobic acrylic IOLs demonstrated the best stability.

IOL designs were important to improve the stability of IOL rotation [34]. Evidence showed that the loop-haptic design IOLs had better rotational stability than the plate- haptic (OR: 0.264, 95\% CI: 0.160-0.436, $P<0.001$ ). Comparing the loop-haptic and plate-haptic IOLs, Patel [35] reported that the plate-haptic tended to rotate more than the loop-haptic design in the early postoperative period. A loophaptic was prone to a double counterclockwise turn after surgery. Venkataraman et al. [10] also observed that loophaptic IOLs had excellent stability while early postoperative IOL rotation was more likely to occur only in larger diameter bags.

The Acrysof toric IOLs presented with the best postoperative stability considering the use of different products, followed by TECNIS and Staar IOLs. Acrysof toric IOLs are composed of a hydrophobic acrylate material, which has a particularly strong adhesion. Besides, the loop-haptic demonstrates good memory and softness that can be used to resolve the optical fluctuations caused by shrinkage of the capsular bag. Moreover, it shows a good stability in the capsular bag. Visser et al. [36] reported pooled estimates for the misalignment of more than $10^{\circ}$, indicating the need for a surgical repositioning $3 \%$. Other clinical studies showed that postoperative rotation of Acrysof IOLs is most likely less 


\begin{tabular}{|c|c|c|c|c|c|c|c|c|c|c|c|}
\hline Study & Events & Total & & & & & & Proportion & $95 \%-\mathrm{CI}$ & $\begin{array}{c}\text { Weight } \\
\text { (fixed \%) }\end{array}$ & $\begin{array}{c}\text { Weight } \\
\text { (random \%) }\end{array}$ \\
\hline Dardzhikova 2009 & 2 & 111 & $1+$ & & & & & 0.02 & {$[0.00 ; 0.06]$} & 5.7 & 5.7 \\
\hline Venkataraman 2013 & 4 & 122 & $\frac{1}{1}$ & & & & & 0.03 & {$[0.01 ; 0.08]$} & 6.3 & 6.3 \\
\hline Miyake 2014 & 4 & 378 & + & & & & & 0.01 & {$[0.00 ; 0.03]$} & 19.6 & 19.6 \\
\hline Chang 2009 & 3 & 263 & + & & & & & 0.01 & {$[0.00 ; 0.03]$} & 13.6 & 13.6 \\
\hline Xing 2010 & 1 & 46 & 1 & & & & & 0.02 & {$[0.00 ; 0.12]$} & 2.4 & 2.4 \\
\hline $\mathrm{Fu} 2010$ & 1 & 48 & 1 & & & & & 0.02 & {$[0.00 ; 0.11]$} & 2.5 & 2.5 \\
\hline Lee $2018 \mathrm{~A}$ & 10 & 626 & $\doteqdot$ & & & & & 0.02 & {$[0.01 ; 0.03]$} & 32.4 & 32.4 \\
\hline Holland 2010 & 1 & 256 & +1 & & & & & 0.00 & {$[0.00 ; 0.02]$} & 13.3 & 13.3 \\
\hline Visser 2014 & 1 & 82 & $\frac{1}{1}$ & & & & & 0.01 & {$[0.00 ; 0.07]$} & 4.2 & 4.2 \\
\hline \multirow{3}{*}{$\begin{array}{l}\text { Fixed effect model } \\
\text { Random effects model } \\
\text { Heterogeneity: } I^{2}=0 \%\end{array}$} & & \multirow[t]{2}{*}{1932} & $\phi$ & & & & & & {$[0.01 ; 0.02]$} & 100.0 & -- \\
\hline & & & $\dot{\phi}$ & & & & & \multirow[t]{2}{*}{0.01} & \multirow[t]{2}{*}[0.01;0.02]{} & -- & \multirow{2}{*}{100.0} \\
\hline & $0, p=0$. & & 0.02 & 0.04 & 0.06 & 0.08 & 0.1 & & & & \\
\hline
\end{tabular}

(a)

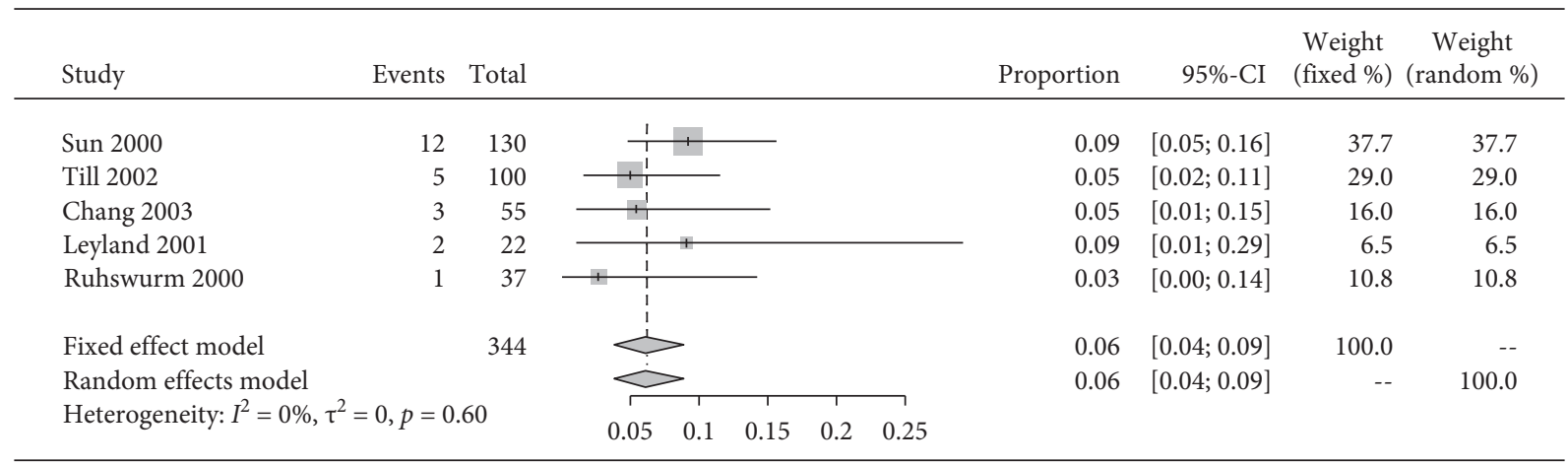

(b)

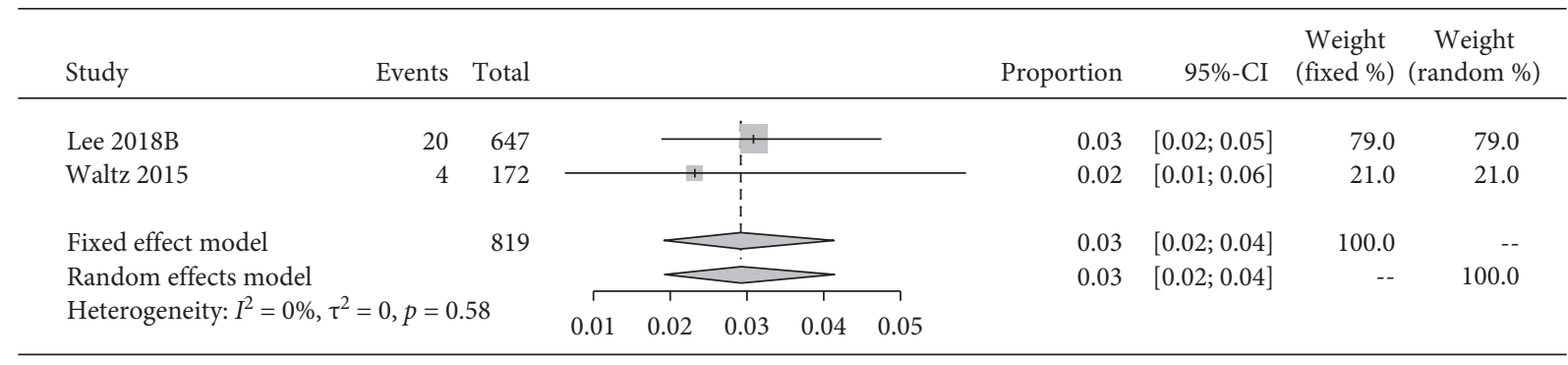

(c)

Figure 5: The forest plots displaying the pooled incidence rate of repositioning surgery of (a) Acrysof toric IOLs, (b) Staar IOLs, and (c) TECNIS toric IOLs.

TABLE 3: Pairwise comparison of multiple sample rates by the partitions of the $\chi 2$ method.

\begin{tabular}{|c|c|c|c|c|}
\hline Subgroup & Sample & No. of samples & $\chi^{2}$ & $P$ value \\
\hline Acrysof & 27 & 1905 & \multirow{3}{*}{38.011} & \multirow{3}{*}{$\leq 0.001$} \\
\hline Staar & 23 & 321 & & \\
\hline Total & 40 & 2226 & & \\
\hline Acrysof & 27 & 1905 & \multirow{3}{*}{7.428} & \multirow{3}{*}{0.006} \\
\hline TECNIS & 24 & 795 & & \\
\hline Total & 51 & 2700 & & \\
\hline Staar & 23 & 321 & \multirow{3}{*}{8.811} & \multirow{3}{*}{0.003} \\
\hline TECNIS & 24 & 795 & & \\
\hline Total & 47 & 1116 & & \\
\hline
\end{tabular}

${ }^{*} P<0.0125$ was considered statistically significant. 


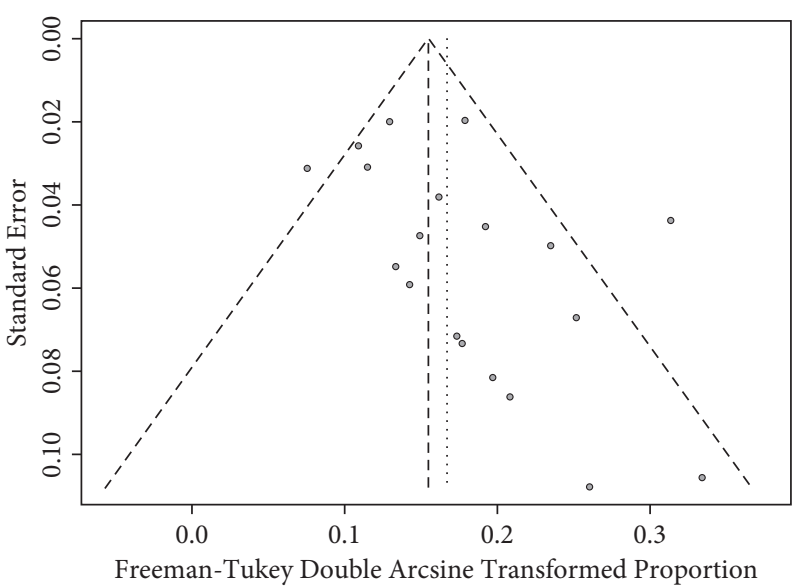

(a)

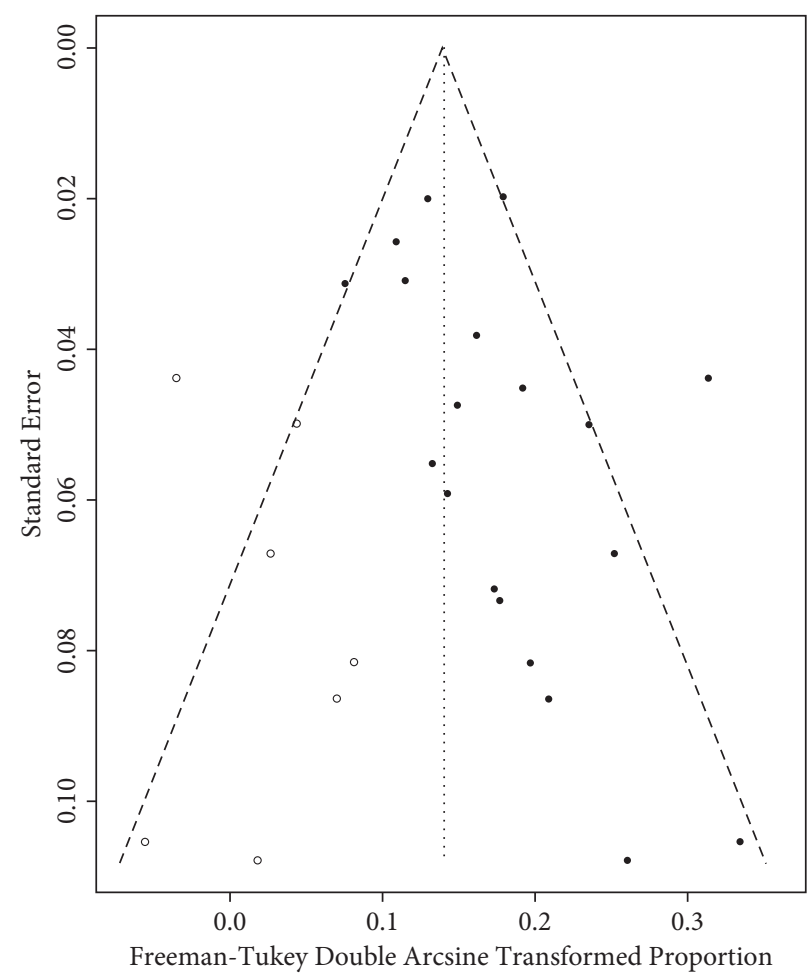

(b)

FIgURE 6: (a) The funnel plot displaying the pooled incidence rate of repositioning surgery of toric IOLs. (b) The filled funnel plot with pseudo-95\% CI (the pseudo-95\% confidence interval (CI) is computed as part of the analysis that produces the funnel plot).

than $5^{\circ}[22,37,38]$, with the long AXL, WTR, and oblique astigmatism being risk factors for toric IOLs rotation $[39,40]$. TECNIS IOLs have designs and materials similar to those of Acrysof, indicating the presence of a good degree of stability [41]. Hirnschall et al. [42] reported that the average rotation of TECNIS IOLs was $3.27 \pm 2.37^{\circ}$. However, we found that the pooled incidence rate of repositioning surgery of TECNIS was higher than that of the Acrysof group (OR: 0.469, 95\% CI: 0.269-0.819, =0.006). Xue et al. [27] also reported 3 eyes ( $9 \%$ ) that required further surgery to rectify the significant IOL rotation. Interestingly, Staar IOLs have a higher postoperative rotation; however, their shorter TF may be considered as one of the risk factors [12, 14, 29]. Chang et al. [13] reported that the TL Staar toric IOLs rotational and repositioning rates were higher than those of TF IOLs. Adequate length is a critical factor to improve the rotational stability of Staar toric IOLs, highlighting the fact that priority should be given to longer IOLs.

Only 4 of 864 eyes demonstrated a failure for repositioning surgery. Among them, Sun et al. [12] reported that the fibrosis of the capsule caused a significant degree of rotation after repositioning, which limited the effect of the position. Xue et al. [27] reported that the reason for the large degree of rotation after surgery was the fact that the patient underwent a preoperative vitrectomy procedure, which decreased the stability of the suspensory ligament. Most clinical studies determined that the IOLs reorientation should be performed within 1 to 3 weeks $[26,29]$. Prematurely calibrating the same may rotate the lens again; however, a delay in calibration may become firmly fix the IOLs in the capsule, which upon rotation may cause a zonular rupture $[22,27,29]$. Therefore, good stability can be ensured by selecting appropriate timing of the repositioning procedure and assessing the patient's complications.

Above all, limitations of this study must be considered. First, most studies involved here were observation trials and therefore lacked well-designed randomized double-blind controls. Second, there were no predetermined common criteria for the repositioning surgery. The need for surgical intervention was purely decided by the surgeons responsible for the same, due to which the repositioning surgery was repeated if the patient provided for the same. However, in the absence of the patient's consent, further treatment was not performed. Alternatively, in cases where the patient was dissatisfied with the postoperative corrected vision, regardless of the minimum rotation degree, the case was inadvertently assigned for another survey. Finally, the funnel plot analysis showed some asymmetry that indicated the possibility of sample bias.

\section{Conclusions}

This meta-analysis suggested that the combined incidence of toric IOLs was $2 \%$, which was lower than that reported in the current literature. There is a significant difference in the incidence with the use of different materials, with a lower incidence with regard to the hydrophobic acrylate and the loop-haptic group. Acrysof toric IOLs have better 
postoperative stability than TECNIS and Staar. Further high-quality studies with more randomized double-blind control designs are needed.

\section{Abbreviations \\ IOLs: Toric intraocular lenses \\ CI: Confidence interval.}

\section{Data Availability}

All data generated or analyzed during this study are included in relevant published articles.

\section{Conflicts of Interest}

All authors of this manuscript declare that there are no conflicts of interest and have no financial relationship with organizations.

\section{Authors' Contributions}

JW and CPY contributed equally to this work and drafted the manuscript. JW and HW conceived and designed the study. JW, CPY, and YY contributed to acquisition of data. JW, CPY, and LIL analyzed and interpreted the data. YY, LIL, and HW revised the manuscript critically for important intellectual content. All authors read and approved the final manuscript.

\section{Acknowledgments}

The authors thank Dr. Wei Wang, from Eye center, Second Affiliated Hospital of Zhejiang University, for the helpful critical reading of the manuscript and Qing Deng and Minghua Dong, from Gannan Medical University, for the help with statistical analysis.

\section{Supplementary Materials}

Supplementary Table: characteristics of studies included in the meta-analysis. The data were subsequently extracted from the included studies using a standardized form: name of the first author, publication year, country, age range, sample size, case, follow-ups, and toric types. (Supplementary Materials)

\section{References}

[1] N. Visser, H. J. M. Beckers, N. J. C. Bauer et al., "Toric vs. aspherical control intraocular lenses in patients with cataract and corneal astigmatism," JAMA Ophthalmology, vol. 132, no. 12, pp. 1462-1468, 2014.

[2] Y.-C. Liu, M. Wilkins, T. Kim, B. Malyugin, and J. S. Mehta, "Cataracts," The Lancet, vol. 390, no. 10094, pp. 600-612, 2017.

[3] L. Kessel, J. Andresen, B. Tendal, D. Erngaard, P. Flesner, and J. Hjortdal, "Toric intraocular lenses in the correction of astigmatism during cataract surgery," Ophthalmology, vol. 123, no. 2, pp. 275-286, 2016.
[4] N. A. Alpins, "Vector analysis of astigmatism changes by flattening, steepening, and torque," Journal of Cataract and Refractive Surgery, vol. 23, no. 10, pp. 1503-1514, 1997.

[5] M. P. Weikert, A. Golla, and L. Wang, "Astigmatism induced by intraocular lens tilt evaluated via ray tracing," Journal of Cataract and Refractive Surgery, vol. 44, no. 6, pp. 745-749, 2018.

[6] D. Tognetto, A. A. Perrotta, F. Bauci et al., "Quality of images with toric intraocular lenses," Journal of Cataract and Refractive Surgery, vol. 44, no. 3, pp. 376-381, 2018.

[7] H. Bissen-Miyajima, K. Negishi, O. Hieda, and S. Kinoshita, "Microincision hydrophobic acrylic aspheric toric intraocular lens for astigmatism and cataract correction," Journal of Refractive Surgery, vol. 31, no. 6, pp. 358-364, 2015.

[8] X. Zeng, Y. Zhang, J. S. W. Kwong et al., "The methodological quality assessment tools for preclinical and clinical studies, systematic review and meta-analysis, and clinical practice guideline: a systematic review," Journal of Evidence-Based Medicine, vol. 8, no. 1, pp. 2-10, 2015.

[9] A. Dardzhikova, C. R. Shah, and H. V. Gimbel, "Early experience with the AcrySof toric IOL for the correction of astigmatism in cataract surgery," Canadian Journal of Ophthalmology, vol. 44, no. 3, pp. 269-273, 2009.

[10] A. Venkataraman and Kalpana, "Visual outcome and rotational stability of open loop toric intraocular lens implantation in Indian eyes," Indian Journal of Ophthalmology, vol. 61, no. 11, pp. 626-629, 2013.

[11] T. Miyake, K. Kamiya, R. Amano, Y. Iida, S. Tsunehiro, and K. Shimizu, "Long-term clinical outcomes of toric intraocular lens implantation in cataract cases with preexisting astigmatism," Journal of Cataract and Refractive Surgery, vol. 40, no. 10, pp. 1654-1660, 2014.

[12] X.-Y.Sun, "Toric intraocular lenses for correcting astigmatism in 130 eyes," Ophthalmology, vol. 2000, no. 107, pp. 1776-1782, 2000.

[13] D. F. Chang, "Early rotational stability of the longer Staar toric intraocular lens," Journal of Cataract \& Refractive Surgery, vol. 2003, no. 29, pp. 935-940, 2003.

[14] M. Leyland, E. Zinicola, P. Bloom, and N. Lee, "Prospective evaluation of a plate haptic toric intraocular lens," Eye, vol. 15, no. 2, pp. 202-205, 2001.

[15] I. Ruhswurm, U. Scholz, M. Zehetmayer, G. Hanselmayer, C. Vass, and C. Skorpik, "Astigmatism correction with a foldable toric intraocular lens in cataract patients," Journal of Cataract \& Refractive Surgery, vol. 26, no. 7, pp. 1022-1027, 2000.

[16] D. J. De Silva, Y. D. Ramkissoon, and P. A. Bloom, "Evaluation of a toric intraocular lens with a Z-haptic," Journal of Cataract and Refractive Surgery, vol. 32, no. 9, pp. 1492-1498, 2006.

[17] D. F. Chang, "Repositioning technique and rate for toric intraocular lenses," Journal of Cataract and Refractive Surgery, vol. 35, no. 7, pp. 1315-1316, 2009.

[18] F. Shu-hua, W. Chang-yun, L. Fei, Z. Qian, and G. Fu, "Clinical study of AcrySof(R) Toric intraocular lens implantation on corneal astigmatism," Chinese Journal of Practical Ophthalmology, vol. 28, no. 8, pp. 881-883, 2010.

[19] X. Qian, G. Huai-jin, and W. Jian, "The study of Toric intraocular lens for corneal astigmatism correction in cataract patients," Chinese Journal of Practical Ophthalmology, vol. 28, no. 11, pp. 1199-1202, 2010.

[20] K. Vandekerckhove, "Rotational stability of monofocal and trifocal intraocular toric lenses with identical design and material but different surface treatment," Journal of Refractive Surgery, vol. 34, no. 2, pp. 84-91, 2018. 
[21] M. Entabi, F. Harman, N. Lee, and P. A. Bloom, "Injectable 1piece hydrophilic acrylic toric intraocular lens for cataract surgery: efficacy and stability," Journal of Cataract and Refractive Surgery, vol. 37, no. 2, pp. 235-240, 2011.

[22] B. S. Lee and D. F. Chang, "Comparison of the rotational stability of two toric intraocular lenses in 1273 consecutive eyes," Ophthalmology, vol. 125, no. 9, pp. 1325-1331, 2018.

[23] K. L. Waltz, K. Featherstone, L. Tsai, and D. Trentacost, "Clinical outcomes of TECNIS toric intraocular lens implantation after cataract removal in patients with corneal astigmatism," Ophthalmology, vol. 122, no. 1, pp. 39-47, 2015.

[24] E. Holland, S. Lane, J. D. Horn, P. Ernest, R. Arleo, and K. M. Miller, "The AcrySof toric intraocular lens in subjects with cataracts and corneal astigmatism," Ophthalmology, vol. 117, no. 11, pp. 2104-2111, 2010.

[25] C. Kaindlstorfer, M. Kneifl, P. Reinelt, and U. Schönherr, "Rotation of a toric intraocular lens from neodymium:YAG laser posterior capsulotomy," Journal of Cataract and Refractive Surgery, vol. 44, no. 4, pp. 510-511, 2018.

[26] T. Oshika, M. Inamura, Y. Inoue et al., "Incidence and outcomes of repositioning surgery to correct misalignment of toric intraocular lenses," Ophthalmology, vol. 125, no. 1, pp. 31-35, 2017.

[27] K. M. Xue, J. K. Jolly, S. P. Mall, S. Haldar, P. H. Rosen, and R. E. MacLaren, "Real-world refractive outcomes of toric intraocular lens implantation in a United Kingdom National Health Service," BMC Ophthalmology, vol. 18, 2018.

[28] D. F. Chang, "Comparative rotational stability of single-piece open-loop acrylic and plate-haptic silicone toric intraocular lenses," Journal of Cataract and Refractive Surgery, vol. 34, no. 11, pp. 1842-1847, 2008.

[29] J. S. Till, P. R. Yoder, T. K. Wilcox, and J. L. Spielman, “Toric intraocular lens implantation: 100 consecutive cases," Journal of Cataract and Refractive Surgery, vol. 28, no. 2, pp. 295-301, 2002.

[30] S. Duval and R. Tweedie, "Trim and fill: a simple funnel-plotbased method of testing and adjusting for publication bias in meta-analysis," Biometrics, vol. 56, no. 2, pp. 455-463, 2000.

[31] M. Lombardo, G. Carbone, G. Lombardo, M. P. De Santo, and R. Barberi, "Analysis of intraocular lens surface adhesiveness by atomic force microscopy," Journal of Cataract and Refractive Surgery, vol. 35, no. 7, pp. 1266-1272, 2009.

[32] R. J. Linnola, M. Sund, R. Ylönen, and T. Pihlajaniemi, "Adhesion of soluble fibronectin, vitronectin, and collagen type IV to intraocular lens materials," Journal of Cataract and Refractive Surgery, vol. 29, no. 1, pp. 146-152, 2003.

[33] P. Draschl, N. Hirnschall, N. Luft et al., "Rotational stability of 2 intraocular lenses with an identical design and different materials," Journal of Cataract and Refractive Surgery, vol. 43, no. 2, pp. 234-238, 2017.

[34] G. D. Shah, M. R. Praveen, A. R. Vasavada, V. A. Vasavada, G. Rampal, and L. R. Shastry, "Rotational stability of a toric intraocular lens: influence of axial length and alignment in the capsular bag," Journal of Cataract and Refractive Surgery, vol. 38, no. 1, pp. 54-59, 2012.

[35] C. K. Patel, S. Ormonde, P. H. Rosen, and A. J. Bron, "Postoperative intraocular lens rotation," Ophthalmology, vol. 106, no. 11, pp. 2190-2196, 1999.

[36] N. Visser, N. J. C. Bauer, and R. M. M. A. Nuijts, “Toric intraocular lenses: historical overview, patient selection, IOL calculation, surgical techniques, clinical outcomes, and complications," Journal of Cataract and Refractive Surgery, vol. 39, no. 4, pp. 624-637, 2013.
[37] S. A. Seth, R. K. Bansal, P. Ichhpujani, and N. G. Seth, "Comparative evaluation of two toric intraocular lenses for correcting astigmatism in patients undergoing phacoemulsification," Indian Journal of Ophthalmology, vol. 66, no. 10, pp. 1423-1428, 2018.

[38] D. Schartmüller, L. Schwarzenbacher, E. L. Meyer, S. Schriefl, C. Leydolt, and R. Menapace, "Comparison of long-term rotational stability of three commonly implanted intraocular lenses," American Journal of Ophthalmology, vol. 220, pp. 72-81, 2020.

[39] X. Zhu, W. He, K. Zhang, and Y. Lu, "Factors influencing 1year rotational stability of AcrySof Toric intraocular lenses," British Journal of Ophthalmology, vol. 100, no. 2, pp. 263-268, 2016.

[40] A. Haripriya, S. Gk, I. Mani, and D. F. Chang, "Comparison of surgical repositioning rates and outcomes for hydrophilic vs. hydrophobic single piece acrylic toric IOLs," Journal of Cataract \& Refractive Surgery, vol. 43, 2020.

[41] B. A. Kramer, D. R. Hardten, and J. P. Berdahl, "Rotation characteristics of three toric monofocal intraocular lenses," Clinical Ophthalmology, vol. 14, pp. 4379-4384, 2020.

[42] N. Hirnschall, S. Maedel, M. Weber, and O. Findl, "Rotational stability of a single-piece toric acrylic intraocular lens: a pilot study," American Journal of Ophthalmology, vol. 157, no. 2, pp. 405-411, 2014. 